Doi: http://dx.doi.org/10.1590/1809-4430-Eng.Agric.v36n 3errata/2016

\title{
ERRATA
}

No artigo "SOFTWARE TO ASSESS BEEF CATTLE BODY MASS THROUGH THE FUZZY BODY MASS INDEX”, com número de DOI: 10.1590/1809-4430-Eng.Agric.v36n1p179193/2016, publicado no periódico revista Engenharia Agrícola 36 (1):179-193, na página 179:

Onde se lia:

\author{
SOFTWARE TO ASSESS BEEF CATTLE BODY MASS THROUGH THE FUZZY BODY \\ MASS INDEX
}

Leia-se:

\section{SOFTWARE TO ASSESS BEEF CATTLE BODY MASS THROUGH THE FUZZY BODY MASS INDEX ${ }^{1}$}

Onde se lia:

\section{LUÍS R. A. GABRIEL FILHO ${ }^{1}$, FERNANDO F. PUTTI ${ }^{2}$, CAMILA P. CREMASCO ${ }^{3}$, DEYVER BORDIN ${ }^{4}$, MARCELO G. M. CHACUR ${ }^{5}$, LUIZ R. A. GABRIEL ${ }^{6}$}

Leia-se:

\section{LUÍS R. A. GABRIEL FILHO ${ }^{2}$, FERNANDO F. PUTTI ${ }^{3}$, CAMILA P. CREMASCO ${ }^{4}$, DEYVER BORDIN ${ }^{5}$, MARCELO G. M. CHACUR ${ }^{6}$, LUIZ R. A. GABRIEL ${ }^{7}$}

Onde se lia:

\footnotetext{
${ }^{1}$ Graduado, Mestre e Livre-Docente em Ma temática, Doutor em Agronomia, Prof. Adjunto, Faculdade de Giências e Engenharia, UNESP - Univ Es tadual Paulis ta, Labora tório de Ma temática Aplicada e Computacional, Tupã - SP, Fone: (14) 3404-4200, gabrielfilho@tupa.unesp.br

${ }^{2}$ Ba cha rel em Administra ção, Mestre e Doutor em Agronomia, Prof. Assistente Doutor, Faculdade de Gências e Engenharia, UNESP - Univ Es tadual Paulista, Tupã - SP; UNIFENAS - Univ José do Rosário Vellano, Alfenas - MG, fe rnandoputti @tupa.unesp.br

${ }^{3}$ Graduada e Mestre em Ma temática, Doutora em Agronomia, Prof. Assistente Doutor, Faculdade de Ciências e Engenharia, UNESP Univ Esta dual Paulis ta, Tupã - SP, camila@tupa.unesp.br

${ }^{4}$ Bacharel em Administração, Tecnólogo em Análise e Desenvolvimento de Sistemas, Mestre em Agronegócio e Desenvolvimento, Doutorando em Agronomia, deyverbordin@fca.unesp.br

${ }^{5}$ Médico Veterinário, Prof. Doutor, UNOESTE - Univdo Oes te Paulista, Presidente Prudente - SP, chacur@unoeste.br

${ }^{6}$ Graduado, Mes tre e Livre-Docente em Ma temática, Doutor em Agronomia. Iragabriel tupa @gmail.com Recebido pelo Conselho Editorial em: 27-6-2014
}

Aprovado pelo Conselho Editorial em: 09-7-2015 
Leia-se:

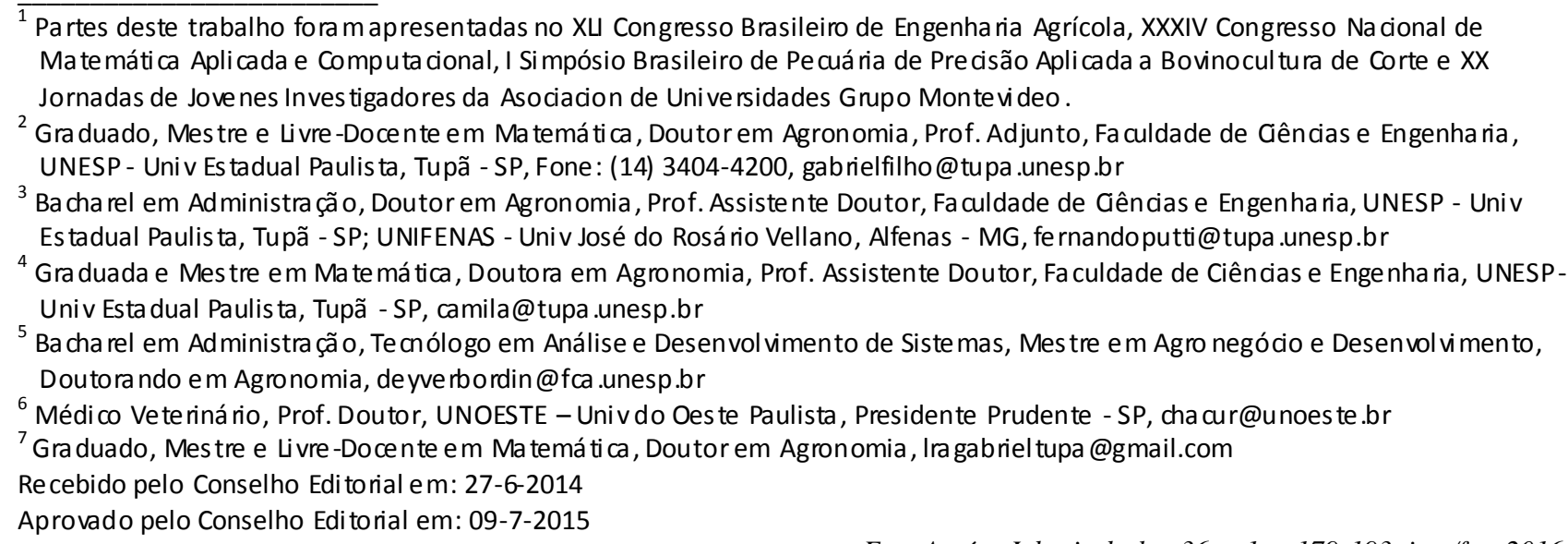

Na página 184, onde se lia:

$$
\begin{aligned}
& \text { FuzzySet } \square^{1}:\left|\begin{array}{ccc}
x & y & \mathbf{1} \\
P_{i} & 0 & 1 \\
P_{i+1} & 1 & 1
\end{array}\right|=0 \Rightarrow-x+\left(P_{i+1}-P_{i}\right) y+P_{i}=0 \Rightarrow y=\frac{x-P_{i}}{P_{i+1}-P_{i}} \\
& \text { Leia }- \text { se }
\end{aligned}
$$

FuzzySet $1:\left|\begin{array}{lll}x & y & 1 \\ P_{i} & 0 & 1 \\ P_{i+1} & 1 & 1\end{array}\right|=0 \Rightarrow-x+\left(P_{i+1}-P_{i}\right) y+P_{i}=0 \Rightarrow y=\frac{x-P_{i}}{P_{i+1}-P_{i}}$ 